\title{
STRATEGI WANITA RAWAN SOSIAL EKONOMI (WRSE) SEBAGAI UPAYA PEMENUHAN KEBUTUHAN HIDUP (Studi di Kelurahan Punggaloba, Kecamatan Kendari Barat, Kota Kendari)
}

Dewiyanti $^{1}$, Bahtiar ${ }^{2}$, Bakri Yusuf ${ }^{3}$

${ }^{123}$ Fakultas Ilmu Sosial dan Ilmu Politik Universitas Halu Oleo

E-mail: Dewiy7819@gmail.com, bahtiarunhalu@yahoo.co.id, bakriyusuf0811@gmail.com

\section{d.}

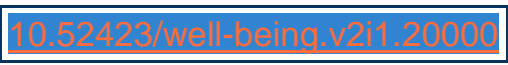

ABSTRACT

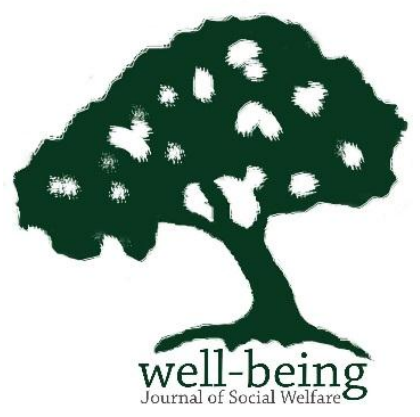

This study aims to determine the strategies undertaken by women who are prone to socioeconomics (WRSE) in Punggaloba Village and to determine the inhibiting factors for women who are prone to socio-economics (WRSE) in an effort to meet the needs of life in Pungggaloba Village. This type of research is a qualitative descriptive study. The data collection technique was done by means of observation, interview and documentation with 7 WRSE informants in Punggaloba Village. The results of the research on the strategies carried out by WRSE in Punggaloba Village utilized their own WRSE skills and established small businesses to support all the needs in the family or the WRSE itself. And the inhibiting factor for WRSE is the lack of knowledge or education possessed by a WRSE because some of them have only graduated from junior high school, and most of them do not get assistance from the government which makes WRSE in Punggaloba Village, they have to struggle to meet their daily needs.

Keywords: Strategy, Life Needs, Socio-Economic Vulnerable Women

\section{PENDAHULUAN}

Menjadi keluarga harmonis adalah harapan setiap manusia yang telah membangun sebuah keluarga. Akan tetapi, kebanyakan dari setiap keluarga tidak mendapatkan keberuntungan dan terkadang berada pada kondisi yang memaksa setiap anggota keluarga untuk bekerja. Sebagai salah satu penyebabnya adalah kemiskinan. Dimana kemiskinan merupakan masalah pembangunan yang di tandai dengan pengangguran, keterbelakangan, dan keterpurukan.Dalam keluarga miskin, perempuanlah yang senantiasa menjadi penyelamat bagi perekonomian keluarga, perempuan yang dianggap menjadi penyelamat bagi perekonomian dikarenakan oleh berbagai peran perempuan miskin yang diambil dalam keluarga yang dimana, pertama sebagai pengelola keuangan keluarga, kedua sebagai penanggung jawab seluruh pekerjaan domestik, ketiga sebagai pencari nafkah keluarga. Hirini dan listyaningsing
(2000) menjelaskan wanita kepala rumah tangga adalah wanita yang dianggap bertanggung jawab terhadap rumah tangganya, yaitu: (1) wanita tidak kawin yaitu wanita yang tidak terikat dengan perkawinan dan bertanggung jawab terhadap rumah tangganya (2) wanita kawin yaitu wanita yang terikat dalam perkawinan tetapi tempat tinggalnya terpisah dengan suami sehingga wanita tersebut mengepalai rumah tangganya (3) wanita cerai hidup atau cerai mati dan belum menikah lagi dan tidak kembali ke keluarga yang melahirkan atau mertua.

Kehidupan Wanita Rawan Sosial Ekonomi (WRSE) yang merupakan kerja sama antara Pusat Data Informasi Kesejahteraan Sosial Kementerian Sosial RI Dengan Badan Pusat Statistik RI tahun 2010 adalah tergolong kelompok miskin (hidup dibawah garis kemiskinan). Kemiskinan adalah keadaan dimana masyarakat tidak mampu untuk memenuhi kebutuhan dasar seperti makanan, pakaian, 
tempat berlindung, pendidikan, dan kesehatan.

Salah satu fenomena sosial yang dapat dilihat dalam kehidupan masyarakat adalah adanya penduduk penyandang masalah kesejahteraan sosial (PMKS) salah satunya adalah Wanita Rawan Sosial Ekonomi (WRSE). Menurut Dinas Sosial (2015) Wanita Rawan Sosial Ekonomi adalah seorang wanita dewasa yang belum menikah atau janda yang tidak mempunyai penghasilan cukup untuk dapat memenuhi kebutuhan pokok sehari-hari dengan ciriciri wanita dewasa, belum menikah (adalah wanita anak fakir miskin) atau janda (adalah wanita sebagai wanita kepala keluarga). Wanita Rawan Sosial Ekonomi (WRSE) kebanyakan berasal dari keluarga yang kurang mampu dan sering kali mendapat pandangan negatif dari masyarakat sekitarnya. Mereka tidak diberikan kesempatan untuk mendapatkan hak yang sama karena diskriminasi dari orang lain.

Selanjutnya Idris dan Selvaratnam (2012) menyebutkan bahwa insiden kemiskinan baik secara relative atau absolut adalah tinggi dikalangan wanita terutama bagi wanita yang menjadi kepala rumah tangga. Bagi wanita yang bercerai hidup atau mati mereka bisa menjadi miskin serta merta jika terpaksa menanggung anak tanpa nafkah atau harta yang ditinggalkan. Kemiskinan dikalangan ibu tunggal harus diberi perhatian mengingat dia dapat memberi implikasi sosial jika tidak ditangani secara efektif. Namun demikian, untuk mengurangi tingkat kemiskinan dan jumlah wanita miskin tidak dapat dicapai hanya dengan program ekonomi karena adanya nilai-nilai sosial seperti peranan reproduktif yang melekat pada kaum perempuan (misalnya: merawat anak pekerjaan rumah tanggga).

Kebijakan ini tidak sesuai dengan landasan hukumnya yaitu peraturan Daerah Provinsi Nomor 10 Tahun 2012 yang menyebutkan bahwa dalam pelaksanaan kebijakan pemberdayaan WRSE terdorong dan memiliki semangat lebih untuk merubah kehidupan mereka menjadi lebih baik lagi selanjutnya diberikan pelatihan vokasioanal/keterampilan sebagai jalan penghubung agar tujuan tersebut dapat tercapai karena jika hanya sebuah motovasi yang diberikan tanpa adanya pemberian caranya untuk mencapai tujuan tersebut akan sia-sia dan selanjutnya pemberian stimulasi modal untuk mendukung pelatihan yang dilakukan agar pelatihan yang telah dilakukan dapat dijadikan usaha yang serius kedepannya. Seharusnya tahapan seperti itu yang disarankan oleh Peraturan Daerah Provinsi namun dalam pelaksanaanya tidak sesuai, pelaksanaan kebijakan pemberdayaan WRSE pada tahun 2017 langsung diberikan stimulasi modal tanpa adanya pemberian motivasi dan pelatihan vokasional yang mengakibatkan Kelompok Usaha Bersama (KUBE) tersebut tidak memilki arah dan tujuan akan diapakan uang stimulan modal yang diberikan.

Dan untuk target dari kebijakan ini pun tidak tepat sasaran dilihat dari anggota KUBE ada yang berusia lanjut yang mengakibatkan tidak efektifnya dalam pelaksanaan program usaha bersama karena seharusnya jika dilihat dari peraturan daerah kriteria yang tergolong WRSE yaitu wanita usia 19-60 tahun. Jika dari sasarannya tidak tepat seperti ini akan mengakibatkan pada pelaksanaan usahanya pun tidak efektif, dengan usia lanjut seperti ini itu pastinya tidak akan bisa berbuat banyak pada pelaksanaan produksi. Maka tidak salah banyak yang KUBE yang mengalami kegagalan pada 2017.

Di Kelurahan Punggaloba,Kecamatan Kendari Barat, Kota Kendari terdapat Wanita Rawan Sosial Ekonomi (WRSE), berdasarkan survei awal jumlah Wanita Rawan Sosial Ekonomi (WRSE) Di Kelurahan 
Punggaloba Kecamatan Kendari Barat sebanyak 25 orang WRSE yang tersebar di berbagai RT/RW Di Kelurahan Punggaloba.Para WRSE tersebut mempunyai kehidupan yang relatif miskin, namun demikian para WRSE tersebut masih bisa hidup dengan kemampuan yang relatif terbatas.

Dari uraian diatas, maka peneliti tertarik untuk mengambil topik penelitian yang berjudul Strategi Wanita Rawan Sosial Ekonomi (WRSE) Sebagai Upaya Pemenuhan Kebutuhan Hidup (Studi Di Kelurahan Punggaloba, Kecamatan Kendari Barat, Kota Kendari).

\section{METODE PENELITIAN}

Jenis penelitian yang dilakukan oleh penulis adalah deskriptif dengan pendekatan kualitatif. Jenis penelitian ini untuk memberikan gambaran atau menjelaskan secara detail mengenai strategi wanita rawan sosial ekonomi (WRSE) sebagai upaya pemenuhan kebutuhan hidup di Kelurahan Punggaloba, Kecamatan Kendari Barat, Kota Kendari. Informan penelitian dalam penelitian ini adalah para wanita rawan sosial ekonomi (WRSE) di kelurahan Punggaloba, Kecamatan Kendari Barat, Kota Kendari yang berjumlah 7 orang. Adapun pemilihan informan dilakukan dengan teknik purposive sampling penunjuk langsung kepada subyek yang dianggap memiliki pengetahuan tentang permasalahan yang akan diteliti yaitu Strategi Wanita Rawan Sosial Ekonomi (WRSE) Sebagai Upaya Pemenuhan Kebutuhan Hidup.

Adapun jenis data dalam penelitian ini adalah data primer dan sekunder. Dalam penelitian ini untuk mendapatkan data yang diperlukan dalam penelitian ini, penulis menggunakan beberapa teknik pengumpulan data. Adapun teknik pengumpulan data tersebut antara lain:

\section{Pengamatan (observasi)}

Dilihat dari sudut pelaksanaannya, kegiatan observasi yang bersifat langsung (participatif observasion) maupun tidak langsung (non-participatif observasion). Dalam observasi tidak langsung, peneliti tidak terlibat secara langsung dalam proses pembelajaran (tidak berinteraksi langsung dengan objek peneliti), namun hanya merekam segala aktifitas sesuai konteks atau literatur yang diinginkan. Observasi langsung dilakukan dengan adanya keterlibatan secara langsung oleh peneliti dalam proses pembelajaran yang dilakukan dalam suatu ruangan.

\section{Wawancara}

Wawancara adalah teknik pengamatan langsung dalam penelitian melalui pertanyaan-pertanyaan langsung kepada objek, wawancara merupakan alat pengumpulan data untuk memperoleh informasi langsung. Wawancara disini ditunjukkan kepada WRSE di Kelurahan Punggaloba, Kecamatan Kendari Barat, Kota Kendari.

\section{Dokumentasi}

Dokumentasi berupa gambar atau foto pada saat kegiatan berlangsung. Data dan informasi tertulis diperoleh dari kajian litearature, dokumen yang ada tentang upayah Wanita RawanSosial Ekonomi (WRSE) di Kelurahan Punggaloba, Kecamatan Kendari Barat, Kota Kendari.

Teknik analisis data dalam penelitian ini, menggunakan Milles \& Huberman (1992:16) analisis terdiri dari tiga alur kegiatan yang terjadi secara bersamaan yaitu: reduksi data, penyajian data, penarikan kesimpulan/verifikasi. Mengenai ketiga alur tersebut secara lebih lengkapnya adalah sebagai berikut:

\section{Reduksi Data}

Reduksi data diartikan sebagai proses pemilihan, pemusatan perhatian pada penyederhanaan, pengabstrakan, dan transformasi data kasar yang muncul dari catatan-catatan tertulis di lapangan. 
2. Penyajian Data

Miles \& Huberman (1992) membatasi suatu penyajian sebagai sekumpulan informasi tersusun yang memberi kemungkinan adanya penarikan kesimpulan dan pengambilan tindakan. Mereka meyakini bahwa penyajianpenyajian yang lebih baik merupakan suatu cara yang utama bagi analisis kualitatif yang valid, yang meliputi: berbagai jenis matrik, grafik, jaringan dan bagan. Semuanya dirancang guna menggabungkan informasi yang tersusun dalam suatu bentuk yang padu dan mudah diraih.

\section{Penarikan Kesimpulan}

Penarikan kesimpulan menurut Miles \& Huberman (1992) hanyalah sebagian dari satu kehiatan dari konfigurasi yang utuh. Kesimpulan-kesimpulan juga diverifikasi selama penelitian berlangsung. Verifikasi itu mungkin sesingkat pemikiran kembali yang melintas dalam pemikiran penganalisis (peneliti) selama ia menulis, suatu tinjuan ulang pada catatan-catatan lapangan, atau mungkin menjadi begitu seksama dan menghabiskan tenaga dengan peninjauan kembali serta tukar pikiran diantara teman sejawat untuk mengembangkan kesepakatan intersubjektif atau juga upaya-upaya yang luas untuk menempatkan salinan suatu temuan dalam seperangkat data yang lain.

\section{HASIL DAN PEMBAHASAN}

\section{Strategi Wanita Rawan Sosial Ekonomi Dalam Memenuhi Kebutuhan Hidup Sehari-hari di Kelurahan Punggaloba Kecamatan Kendari Barat}

\section{a. Mendirikan Usaha Kecil-Kecilan}

Dalam memenuhi kebutuhan hidupnya sehari-hari wanita rawan sosial ekonomi membutuhkan suatu usaha dapat berupa mendirikan usaha ekonomi semacam warung dan lain sebagainya.
Hal ini pula di lakukan oleh beberapa Wanita Rawan Sosial Ekonomi Di Kelurahan Punggoloba Kecamatan Kendari Barat Berikut hasil wawancara penulis dengan Ibu Yusriani (47) yang menjelaskan tentang starategi dalam pemenuhan kebutuhan hidupnya seharihari

"untuk hidup saya mengadalkan dari usaha warung yang ada dalam rumahku itu seperti pop ice, gorengan, jagung bakar. Selama ini saya tinggal sama orantuaku karena mereka sudah sakitsakitan dan saya juga cerainnya cerai hidup"(Wawancara, 30 November 2020)

Hal ini di perkuat dengan Ibu Suhaebah (60) yang memberikan jawabannya berikut wawancaranya

"saya ini kan nak menyambung rumah dengan anakku disitu saya menjual pisang goreng, bakwan, tahu, dengan tambahannnya kalau pagi-pagi saya seing jual nasi kuning di rumah ku itu apalagi korona ini susah mi kita mau mencari tambahan kemarin ini nak saya sering berjualan di sekolah alhamdulilllah kasian lumayan hasil tapi sekarang nda bisa mi (Wawancara, 26 November 2020 )

Dari pandangan diatas menjelaskan bahwasannya salah satu strategi yang di lakukan oleh Wanita Rawan Sosial Ekonomi Di Kelurahan Punggoloba Kecamatan Kendari Dengan cara menjual melalui warung Sembako atau jualan biasa di depan rumah agar dapat memenuhi kebutuhan hidup mereka masing-masing, walaupun dalam berjualan mereka ada yang menumpang dirumah orang tua dan dengan jualan-jualan yang sangat sederhana.

\section{b. Memanfaatkan Keterampilan Diri}

Dalam menggunakan keterampilan masing-masing individu yang dimiliki oleh 
seorang Wanita Rawan Sosial Ekonomi di perlukan suatu kemampuan yang di miliki.

Berikut hasil wawancara penulis dengan ibu Wahaliana (60) yang memberikan pandangan sebagai berikut

"saya juga dek kalau untuk pekerjaan tidak memiliki pekerjaan apa-apa nda ada keterampilan yang saya miliki baru umur juga sudah tua mi sehingga kasian saya susah untuk memenuhi kebutuhan saya sehari-hari susah sekali dek, ditambah lagi saya juga sakit maka susah juga baru nda ada yang melihat ini mau pemerintah susah sekali kita tidak dapat bantuan sama sekali"(Wawancara,26 November 2020).

Hal ini berbeda halnnya dengan pandangan lannya dari Ibu Wa Ode Bali (53) Kelurahan Punggoloba Kecamatan Kendari Barat yang memberikan jawaban tentang Strategi Wanita Rawan Sosial Ekonomi

"Saya sangat susah untuk kerja kasian karena ada rematik ku itumi sebabnya kenapa saya tidak bisa berbuat banyak juga karena keterbatasan fisik saya ini apalagi umurku ini kasian dek sudah sangat tua jadi saya hanya bisa memanfaatkan kemampuan yang saya miliki yaitu mengurut biasa kasian kalau ada yang sakit saya dipanggil jadi tukang urutnya " (Wawancara,26 November 2020).

Dari penjelasan diatas peneliti melihat terdapat 2 perbedaan penjelasan dari informan wa wahaliana yang mengatakan ketidaksangggupan untuk bekerja karena keadaannya yang sakitsakitan sedangkan hasil wawancara dengan Wa Ode Bali mengatakan tidak bisa berbuat banyak dalam bekerja karena keterbasaan sehingga ia hanya bisa menngandalkan kemampuan yang dimilikinya yaitu jadi tukang urut. Maka dapat disimpulkan bahwasannya ada dua hal mereka berkerja dengan mengadalkan keterampilan dan ada dari mereka tidak mampu melakukan karena keterbatasan fisik yang dimilikinya.

\section{c. Melakukan Pekerjaan Dalam Memenuhi Kebutuhan Hidup}

Dalam kehidupan manusia selalu mengadakan bermacam-macam aktivitas. Salah satu aktivitas itu diwujudkan dalam gerakan-gerakan yang dinamakan kerja. Bekerja mengandung arti melaksanakan suatu tugas yang diakhiri dengan buah karya yang dapat dinikmati oleh manusia yang bersangkutan.

Berikut hasil wawancara penulis dengan salah satu informan penelitian bernama Wa Ode Bali (53) yang memberikan pandangannya tentang Wanita Rawan Sosial Ekonomi harus bekerja

"iye terimakasih dek, saya sebenarnya sebelum sakit-sakitan seperti ini saya kemarin ada usaha sampingan dek, karena sekarang saya sakit Rematik saya susah untuk bekerja karena sakit $\mathrm{ku}$ ini baru nda ada uang juga untuk berobat keluarga ataupun yang lainnya juga kesusahan sama seperti saya maka usaha yang dulu saya punya itu mulai bangkrut sehingga saya seperti ini sekarang" (Wawancara,26 November 2020).

Hal ini juga diperkuat oleh ibu Wa Narti (41) yang memberikan pandangan mengenai kemampuan yang di lakukan untuk mencari nafkah

"saya selain mengandalkan bantuan PKH saya juga mencoba menjadi kuli cuci di rumah tentangga yang ada di sekitar lingkungan $\mathrm{ku}$ untuk dapat memenuhi kebutuhan hidup saya ini merupakan langkah saya atau seperti kata kita strategi saya dalam memenuhi Kebutuhan hidup seharihari"(Wawancara 27 November 2020)

Berdasarkan hasil wawancara penulis dengan informan penelitian ini maka dilihat dari jawaban pertama yang menyatakan ketidaksanggupan lagi untuk 
bekerja di karenakan sakit-sakitan sementara untuk jawaban kedua itu selain mengandalkan bantuan PKH dari pemerintah maka ia juga menjadi kuli cuci pakaian di rumah tetangga.dari beberapa penjelasan diatas maka mengenai kondisi pekerjaan sebagai langkah atau strategi wanita rawan sosial ekonomi dalam memenuhi kebutuhannya sehari-hari di Keluahan Punggaloba Kecamatan Kendari Barat adalah masih banyak yang tidak memiliki pekerjaan di karenakan kondisi mereka yang tidak mampu baik secara fisik maupun intelektual.

2. Faktor-faktor penghambat Wanita Rawan Sosial Ekonomi Di Kelurahan Punggoloba Kecamatan Kendari Barat

a. Faktor Internal

Faktor internal yaitu faktor yang menyebabkan terjadinya suatu masalah yang berasal dari dalam diri perempuan tersebut adalah adanya keterbatasan yang dimiliki antara lain keterbatasan fisik yang disebabkan oleh kekurangan kemampuan fisik untuk melakukan kegiatan serta tingkat intelegensi yang rata-rata masih di bawah kaum pria, masih adanya rasa kurang percaya diri, apatis, rendah diri dan aspek sosial budaya.

Berdasarkan wawancara penulis dengan ibu Suhaebah (60) Kelurahan Punggoloba Kecamatan Kendari Barat yang memberikan jawaban mengenai Faktor penghambat dalam keberfungsian sosialnya di masyarakat sebagai wanita Rawan Sosial Ekonomi

"untuk tempat tinggalnya dek saya itu menyambung rumah sama anak saya itupun di dalam kartu keluarga saya itu cuma saya sendiri,maka dari itu untuk kebutuhanku saja susah apalagi kalau saya memenuhi kebetuhan keluarga ku semacam anakku, untuk sekolah saja saya itu hanya tamatan SMP tidak ada bakat yang saya punya dek" (Wawancara,26 November 2020 )
Sama halnya dengan ibu Wa Ode Bali (53) Kelurahan Punggoloba Kecamatan Kendari Barat yang memberikan jawaban tentang faktor penghambat Wanita Rawan Sosial Ekonomi

"sekarang ini kita kan sudah umuran apalagi dengan kondisi sekarang sudah tua sakit-sakitan kaki kadang susah jalan ya itulah yang mungkin hambat saya" (Wawancara,26 November 2020).

Berdasarkan dua jawaban diatas dapat dilihat bahwasannya di dalam faktor penghambat Wanita Rawan Sosial Ekonomi dalam Faktor internal di jelaskan bahwasannya terdapat beberapa hal sepeti kurangnnya pengetahuan atau pendidikan yang dimiliki oleh seorang WRSE dikarenakan dari mereka ada yang hanya tamatan SMP, serta faktor internal lainnya berasal dari keterbatasan fisik atau umur dalam hal ini Wanita Rawan Sosial Ekonomi di Kelurahan Punggaloba Kecamatan Kendari Barat berdasarkan hasil wawancara diatas mereka terlampau kedalam lanjut usia serta ada dari mereka mengalami sakit-sakitan di karenakan faktor Umur tersebut.

\section{b. Faktor Ekternal}

Wanita rawan sosial ekonomi memiliki permasalahan bukan hanya berasal dari faktor internal tetapi berasal dari faktor eksternal.Faktor eksternal yaitu faktor yang berasal dari luar diri WRSE adalah kurangnya kesempatan untuk memperoleh pekerjaan, distribusi pendapatan yang kurang merata dan diskriminasi yang mereka alami dalam mendapatkan pekerjaan. terdapat empat kategori yaitu : dukungan keluarga,manajemen waktu, relasi sosial.

Berdasarkan wawancara penulis dengan Ibu Aspati (62) yang memberikan penjelasan mengenai faktor Ekternal penghambat Wanita Rawan Sosial 
Ekonomi di Kelurahan Punggoloba Kecamatan Kendari Barat

"saya tinggal sama anak saya yang sudah menikah selama masa sekarang ini tidak terima apa-apa kasian, bantuan yang saya dapat itupun karena korona ini mungkin kalau tidak ada korona saya tidak dapat bantuan apaapa karena susah juga kita mau mengaharapkan bantuan itu sendiri “ (Wawancara, 30 November 2020)

Sama halnya dengan jawaban dari Ibu Suhaebah (60) yang memeberikan jawabannya beikut wawancaranya

"tidak menerima bantuan sama sekali apapun itu hanya anak saya sebagai penerima bantuan kita juga coba mengurus mungkin karena sudah tua jadi tidak dapat ya mau diapakan juga terima saja" (Wawancara, 26 November 2020 )

Hal ini bertentangan dengan jawaban dari Ibu Narti (41) yang memeberikan penjelasannya mengenai Faktor Ekternal Penghambat Wanita Rawan Sosial Ekonomi Di Kelurahan Punggaloba Kecamatan Kendari Barat berikut jawaban wawancarannya.

"saya tinnggal sendiri suami saya sudah meninggal tahun lalu saya mengurus anak-anak saya alhamdulillah saya menerima bantuan dari kelurahan ya sedikit banyaknnya bisa membantu saya dalam kehidupan sehari-hari (Wawancara 27 November 2020)

Berdasarkan hasil wawancara diatas maka dapat ditarik kesimpulan mengenai Faktor Ekternal Penghambat Wanita Rawan Sosial Ekonomi Di Kelurahan Punggaloba Kecamatan Kendari Barat, kebanyakan dari mereka tidak mendapatkan fasilitas bantuan dari pemerintah yang membuat WRSE Di Kelurahan Punggaloba Kecamatan Kendari Barat,harus berjuang dalam memenuhi kebutuhan hidup sehari-hari hal ini terlihat dari jawaban wawancara diatas ada dari mereka yang mengadalkan anaknya dalam memenuhi kebutuhan hidup sehari-harinya.

c. Faktor Pendukung Wanita Rawan Sosial Ekonomi Di Kelurahan Punggaloba Kecamatan Kendari Barat Kota Kendari

Wanita Rawan Sosial Ekonomi adalah wanita dewasa belum menikah atau sudah menikah atau sudah janda tidak mempunyai penghasilan yang cukup untuk dapat memenuhi kebutuhan pokoknya sehari-hari dalam penelitianya kelompok wanita masih mendominasi sebagai kelompok yang rentan terhadap penyandang WRSE.

Ibu Narti (41) memberikan pandanggannya mengenai faktor pendukung yang di dapatnya

"ehhh saya ini kan janda sudah tidak memiliki suami tapi alhamdulillah saya bisa mampu menghidupkan anak saya saya tidak malu atau bagaimana-bagaimana yang penting yang saya lakukan bukan dosa besar minta ya alhamdulillah kita dikasi juga bantaun PKH seperti yang saya sudah bilang sebelumnya " (27 November 2020)

Hal ini diperkuat kembali oleh Ibu Aspati (62) yang menjelaskan mengena faktor pendukung Wanita Rawan Sosial Ekonomi Di Kelurahan Punggaloba Kecamatan Kendari Barat Kota Kendari "ya faktor pendukungannya mungking dek itumi bantuan BLT yang saya dapat kasian tapi itupun juga saya dapatnya nanti korona ini kalau tidak ada kororna mungkin saya tidak dapat susah sekali betul saya tidak mau juga minta kasian karena saya takut (Wawancara, 30 November 2020)

Dari kedua penjelasan diatas sebelumnya sudah sedikit disinggung diatas dan pada bagian faktor pendukung 
ini para wanita rawan sosial ekonomi ini di perjelas kembali faktor pendukung berupa apa dan hasilnya ialah didapatkan bantuanbantuan sosial wanita rawan sosial ekonomi dan siikap penerimaan dirinya akan tidak malu dengan status yang dimiliki nya itu.

\section{KESIMPULAN}

Berdasarkan hasil penelitian diatas maka dapat ditarik sebuuah kesimpulan dalam penelitian ini sebagai berikut:

1. Wanita Rawan Sosial Ekonomi Di Kelurahan Punggoloba Kecamatan Kendari dalam memenuhi kebutuhan hidupnya sehari-hari dengan cara mendirikaan usaha warung dan berjualan kecil dan ada salah satu wanita Rawan Sosial Ekonomi Di Kelurahan Punggoloba Kecamatan Kendari hanya bisa megandalkan keterampilan mereka dengan menjadi tukang urut da nada juga dari mereka tidak bisa melakukan hal apapun selain mengandalkan pemasukan dari anaknya. ada dua hal mereka berkerja dengan mengadalkan keterampilan dan ada dari mereka tidak mampu melakukan karena keterbatasan fisik yang dimilikinya.Mengenai kondisi pekerjaan sebagai langkah atau strategi wanita rawan sosial ekonomi dalam memenuhi kebutuhannya sehari-hari di Keluahan Punggaloba Kecamatan Kendari Barat adalah masih banyak yang tidak memiliki pekerjaan di karenakan kondisi mereka yang tidak mampu baik secara fisik maupun intelektual.

2. Faktor penghambat Wanita Rawan Sosial Ekonomi dalam Faktor internal di jelaskan bahwasannya terdapat beberap hal sepeti kurangnnya pengetahuan atau pendidikan yang dimiliki oleh seorang WRSE dikarenakan dari mereka ada yang hanya tamatan SMP, serta faktor lainnya berasal dari keterbatasan fisik atau umur dan mengenai Faktor Ekternal Penghambat Wanita Rawan Sosial Ekonomi kebanyakan dari mereka tidak mendapatkan fasilitas bantuan dari pemerintah yang membuat WRSE Di Kelurahan Punggaloba Kecamatan Kendari Barat,harus berjuang dalam memenuhi kebutuhan hidup sehari-hari.

3. Pada bagian faktor pendukung ini para Wanita Rawan Sosial Ekonomi ini di perjelas kembali faktor pendukung berupa apa dan hasilnya ialah didapatkan bantuanbantuan sosial Wanita Rawan Sosial Ekonomi seperti PKH, BLT dan sikap penerimaan dirinya akan tidak malu dengan status yang dimiliki nya itu.

\section{DAFTAR PUSTAKA}

Dinas Sosial. (2015). Pedoman Umum Pemberdayaan Keluarga, diambil dari http://www.kemsos.go.id/modules.ph $\mathrm{p}$ ? name $=$ glosariumkesos \&letter $=\mathrm{w}$, diakses pada tanggal 14 Maret 2016.

Harini, Rika dan Listyaningsih, Umi. (2000). Perubahan Strategi Bertahan Hidup Wanita Kepala Rumah Tangga di Masa Krisis (Studi Kasus Kecamatan Umbul Harjo Daerah Istimewa Yogyakarta): Majalah Geografi Indonesia, 15 (1), 47-62.

Idris, N.A.H., Selvaratnam, D.P (2012). Program Pembasmian Kemiskinan Dalam Kalangan Ibu Tunggal: Analisis Pernyataan Dan Keberkesanan: Prosiding Persidangan Kebangsaan Ekonomi Malaysia. VII (1), 248-259, ISSN: 2231-962X 
Kementerian Sosial RI and Badan Pusat Statistik, 2011. Profil Wanita Rawan Sosial Ekonomi (WRSE) Indonesia Berdasarkan Data Susenas 2010. Jakarta: Pusat Data dan Informasi Kesejahteraan Sosial Kementrian Sosial RI Bekerja Sama Bada Pusat Statistik RI

Milles \& Huberman. 1992. Analisis Data Kualitatif, Jakarta: Universitas Indonesia Press. 